\title{
Involving and Engaging Parents of Children with IEPs
}

\author{
Kathryn Underwood \\ Ryerson University
}

\begin{abstract}
This study explored parents' views of the educational experience of children with Individual Education Plans. The research goal was to determine how parents are meaningfully involved and engaged in the development and monitoring of education programs for their children. The primary data source for the study was 31 interviews with parents, analysed using qualitative thematic analysis; additional data came from parent questionnaires, which provided further information about parents' experiences. This mixed methods study describes the nature of parent involvement and engagement in schools, particularly in Individual Education Plan development and implementation. The study also examined how parent involvement and engagement (a) relate to parents' satisfaction with school programs and (b) are contextualized within inclusive practice for children with disabilities. The findings of the study are discussed in relation to the broader literature on parent involvement and engagement.
\end{abstract}

Parent and family involvement and engagement in education are now widely accepted as critical to inclusive school practice and as strategies for supporting higher achievement for increasingly diverse student populations (Bouffard \& Weiss, 2008; Epstein, 2001a, 2001b; Pushor \& Murphy, 2004). The view that parent involvement and engagement will improve student outcomes has particular implications for parents of children with Individual Education Plans (IEPs). Parents of children with IEPs are expected to participate in development and monitoring of the plan, as well as meetings to set up the plan.

Parents and school staff participate in a range of joint activities that are referred to as parent involvement, parent participation, parent engagement, family school relationships or collaboration, amongst other descriptors (Pushor, 2007). In Ontario, there have been policy initiatives to strengthen parent "engagement" in schools through parent involvement advisory committees at the provincial and school board level, as well as the establishment of a Parent Engagement Office at the Ministry of Education, which among other activities has been distributing grants for projects that facilitate parent involvement. The terms engagement and involvement are 
used interchangeably in these policy initiatives, but for this study I will distinguish between the terms.

Parent involvement is a more general term than engagement that characterizes interactions between the parents and the school in what Epstein (2001a) referred to as overlapping spheres of influence. Epstein (2001b) identified six types of involvement: parenting, communicating, volunteering, learning at home, decision making, and collaborating with the community. Other researchers have noted that these types of involvement do not necessarily result in real engagement of parents in schools (Corter \& Pelletier, 2004; Pushor \& Murphy, 2004; Wink, 2005). Parent engagement is characterized as being qualitatively different from involvement because it requires relationship building, understanding of experiences on the part of both parents and teachers, and opportunities for parents to have their voices heard in relation to the teaching and learning activities of schools, rather than as fundraisers or in special events. Engagement is also sometimes characterized as having quantifiably different characteristics from involvement; for example, Harris and Goodall (2008) described engagement as happening in the home and involvement as being a school-based activity. For this study, parent involvement refers to those activities that are school directed, but give parents a role in school activities, and parent engagement is the participation of parents in meaningful activities relating to the learning goals of their children, including decision making in instructional activities (Harris \& Goodall, 2008; Pushor \& Murphy, 2004). This study examined the school involvement and engagement experiences of parents with children who have IEPs. The purpose of this study was to explore the current involvement and engagement practices that are employed by schools from the perspective of the parents of children with IEPs. The study also examined the tensions that may arise from these practices and the challenges faced by parents who are involved and engaged in their children's educational experiences.

\section{Outcomes from Parent Involvement}

The goals of parent involvement initiatives are grounded in research that indicates a relationship exists between parent involvement and student achievement (Bouffard \& Weiss, 2008; Epstein, 2001b; Hughes \& Kwok, 2007). However, we, as educators and researchers, should not conclude that parent involvement has a direct and always positive causal effect on student achievement. Domina (2005) noted that evidence of a positive relationship between parent involvement and student achievement is "uneven" in the literature. In a longitudinal study of parent involvement policy effects on student achievement, Domina concluded that parent involvement does not have an independent positive effect on student achievement, but may improve student behaviour. Similarly, Crossnoe, Erickson, and Dornbusch (2002) found that family relationships have a protective effect on student behaviour, but that school effects were greater than family effects. A study of low-income California schools also found that school factors, such as higher expectations, had a greater effect on student achievement than parent involvement (Williams, Kirst, Haertel, et al., 2005). In sum, mixed findings in the literature could be due to the complex relationship between parent involvement and engagement, school practices, and the children themselves. The timing of parent involvement and engagement, the circumstances which lead to parent involvement and engagement, and the other factors that are contributing to a child's learning contribute to student outcomes.

The way in which parent involvement is defined as well as the outcomes measured may change the conclusions that can be drawn about the effect of parent involvement on student 
achievement (Flessa, 2008). Jeynes (2007), in his meta-analysis of urban secondary school parent involvement studies, concluded that there is a greater effect on achievement from "voluntary parent involvement" than from parent involvement resulting from "parent support programs" (p.100). Jeynes found that while some types of parent involvement have a greater effect, such as parenting styles and expectations as opposed to parent involvement in school activities, overall parent involvement had a positive relationship with student achievement. Harris and Goodall (2008) argued that in-home parent engagement, as opposed to school-based parent involvement, has a greater effect on learning and achievement. Studies also indicate a greater effect of parent involvement on student achievement for families with lower socio-economic status (Bouffard \& Weiss, 2008; Domina, 2005), but effects of parent involvement showed no difference across ethnic groups (Jeynes, 2007).

Despite the inconclusive evidence about the power of parent involvement to boost student achievement there is broad public appeal to parent involvement. It can be argued that parent involvement is democratic. The Parent Voice in Education Project (Government of Ontario, 2005), a provincial consultation with parents in Ontario, reported that parents across the province want to see "empowerment of parent voice; a transformation of the system into a more welcoming and inclusive environment for parents; [and] recognizing and addressing the differences among Ontario's diverse communities" (p. 14). Parent involvement is also touted as important for creating inclusive and equitable schools that are responsive to diverse communities. One of the risks, however, is that parents who are not involved may be blamed if their children fail or have low achievement in school. Pushor and Murphy (2004) cautioned that:

Parents are often cast as protagonists, being seen as doing, or not doing, things that interfere with the quest of the protagonist (the teacher) to enhance learning. Parents, most certain to be cast as antagonists, are those who do not meet the white, middle-class values and expectations of the school system. (p. 222)

The implication is that if all parents do not have the opportunity to be heard schools will unfairly disadvantage some children and their families.

\section{Involving Parents of Children with IEPS}

Families of children who have IEPs are asked to be involved in their children's education through the IEP process, which can be very involved and sometimes results in conflict or tension between teachers and families (Ministry of Education, 2007). The Ontario Coalition for Inclusive Education (2003), in their statement of principles said,

[Inclusive] Education includes the provision of support and accommodation as determined by an individualized planning process that includes the meaningful participation of people who love the student. [...] All students benefit from collaboration and cooperation among their home, their school and their community.

Communication between parents and schools is widely accepted as an important component of good practice in serving children with disabilities and in developing IEPs (Dabkowski, 2004). However, parents and school staff do not always share the same goals and perspectives. Engel's (1993) ethnographic study of parents of children with disabilities found conflicting views between parents, the law, and the language of disability specialists. Engel highlighted the importance of cooperative decision making, parent knowledge, and legal empowerment of par- 
ents for positive outcomes for children with disabilities. Hanson et al. (2001) found that family factors, such as the ability to advocate and access information, were an integral component in keeping students in inclusive placements, in addition to professionals' decisions and the placement options available in the school system. Turnbull, Turnbull, Erwin, and Soodak (2006) stressed that trust is critical in developing partnerships and building relationships with families.

In Ontario, the IEP governs the program (not the placement) of students with disabilities. The IEP Standards indicate that parents (and children 16 or older) must be "consulted in the development and review of the student's IEP, and that a copy of the IEP is provided to the parents and the student on its completion" (Ministry of Education, 2000, p. 17). Compliance with the standard requires that a consultation form be attached to the IEP to give "evidence of appropriate consultation" (emphasis added; Ministry of Education, 2000, p. 18). The manner in which the appropriateness of consultation is judged, however, is unclear. According to the IEP Standards, parents should provide information about the child's personality, development, and learning through open communication and cooperation. This is a requirement for parents to provide information, but it does not necessarily lead to shared decision making or parents having a meaningful voice in the education process. Parent involvement for children with disabilities should also be contextualized within the professional discourse of family experiences of disability. Research on families with children who have disabilities has historically focused on the negative experience for the family and on the reactions of families to having a child with disabilities such as stress and denial (Ferguson, 2002; Hauser-Cram, Warfield, Shonkoff, \& Krauss, 2001). In this context, parents report that professionals blame difficulty in parent-teacher relationships on parents' poor adjustment to or denial of a child's disability (Engel, 1993).

The role of parents in the lives of children with disabilities has been assigned by professionals in many ways, as described by Turnbull et al. (2006), from being the cause of a child's disability to recipient of professional advice to advocate for their child and partner with professionals. This is an important historical context for this study. Children with disabilities generally have more interactions with professionals from a young age than other children. There is a long history of professionals judging parents of children with disabilities, and while other parents may be viewed as a positive influence in the lives of their children, this has not always been true for parents of children with disabilities (Berman \& Wilson, 2009; Engel, 1993; Ferguson, 2002). Parents of children with disabilities have been marginalized in the care of their own children (Berman \& Wilson, 2009; Dodds, Saggers, \& Wildy, 2009).

One of the goals of involving parents in development of IEPs and as part of the decisionmaking team for children with disabilities is to achieve inclusion. Mortier, Hunt, Desimpel, and Van Hove (2009) found that commitment to inclusion from parents and teachers resulted in the children being more engaged in their own learning environment. The research on parent involvement indicates that parents who are engaged in true collaborative activities and in the learning experience of their children have the greater impact on student outcomes. For children with IEPs who have accommodations and modifications in place to support them, parent involvement and engagement are expected to be critical to student success. The broad purpose of this study was to identify parent involvement and engagement activities. The specific issues to be addressed are how parents perceive their own involvement and engagement in relation to student achievement, and how these parents describe the challenges that they face specific to the IEP process and/or the learning needs of children with IEPs. 


\section{Method}

The study used a mixed methods research approach. Mixed methods studies include both qualitative and quantitative data strands which are integrated in the results in order to present more comprehensive conclusions than could be presented if the results of the two strands were presented alone (Tashakkori \& Creswell, 2007). The qualitative interview data are analysed using thematic analysis, informed by grounded theory (Boyatzis, 1998; Charmaz, 2008). The qualitative data are supplemented with the quantitative findings of questionnaire data. The two distinct types of data provide different, yet complementary, results that elucidate parent experiences of school involvement and engagement. The mixed methods are useful in that each supports the emergent themes that are identified in the study.

\section{Participants}

Four school boards identified schools where they considered inclusive practices to be currently taking place. Two of the school boards were English language public boards and two were Catholic English language public boards. Eleven elementary schools considered to be "inclusive" were identified. Only one of the school boards had a policy of full inclusion for children with disabilities, meaning they did not offer self-contained classes. Seven of the 11 schools were from that school board. The 11 schools included a mix of urban, suburban, and one rural school. Administrators from these schools were asked to participate in a study about individualized planning. All 11 school principals agreed and an information lunch was held for teachers at these schools where they were asked for their voluntary participation in the study. The teachers who volunteered then sent out letters to parents of children with IEPs asking if the parents would be willing to be interviewed about their experiences with the school. This approach resulted in 31 families who volunteered to participate in the study. Thirty-one interviews were conducted with either one or two parents attending. Of the 31 interviews, 1 was with a father only, 6 were with two parents (including one same-sex family), and 24 were with mothers only. The term "parent" included foster parents and step-parents.

The children in the study had a range of clinical diagnoses and represented all of the categories of exceptionality identified by the Ministry of Education (2000). The 31 children (22 boys, 9 girls) included 6 with developmental disabilities, 3 with mild intellectual disabilities, 17 with learning disabilities (many of whom had multiple conditions including sensory impairments and physical disabilities), and 5 students identified as having disabilities on the Pervasive Developmental Disorder spectrum. While the schools in the study were identified by school board staff as being exemplary for their inclusive practice, the model of service delivery for these students varied dramatically by school. Of the 31 students, 3 were in self-contained classes, 4 in withdrawal programs with some integration in regular classes, 22 were in regular education classes with some support (from a paraprofessional or a resource teacher), and 2 were in regular classes with no additional support as reported on their IEPs. Those in regular education classes, with support or with no additional supports, were considered to be in inclusive placements.

\section{Procedure}

The in-depth interview was based on Engel's (1993) narrative technique called origin myths, which "connect past and present, clarify the meaning of important events, reaffirm core 
norms and values, and assert particular understandings of social order and individual identity" (p. 785). In this study, origin myths are the stories parents told of their first contact with the school system and their ensuing experiences of involvement or engagement with school staff particularly in relation to the IEP. Parents answered four general questions: (a) to describe their child; (b) to describe their first experiences with the school system; (c) to discuss the development of the child's IEP; and (d) to describe how they have worked with their child's teacher and other school staff this year.

Following institutional ethics approval, each parent participated in an in-depth interview lasting approximately 1 hour. In addition, parents gave permission for access to the IEPs of each student. Confidentiality was of utmost concern in this study in order that interviewees could speak freely without risk of affecting the child involved. Many participants expressed that participation was a positive experience which led them to think more deeply about important issues.

At the time of the interview, parents responded to a questionnaire about their participation and satisfaction with programming for their children. The questionnaire, developed for this study, included demographic information as well as six Likert scale questions rating parents' perceptions of IEP development and efficacy (see Appendix for the questionnaire).

All but two of the interviews took place in the school in a private room: One interview was conducted at the family's home and one was conducted by telephone after several attempts were made to meet in person. In both cases, the nature of the parents' employment (farming and shift work) made it difficult to meet at the school. The interviews were audio taped, transcribed, and coded. Initially, interview data were organized across five topics identified in previous research on teacher practices in inclusive education (Jordan \& Stanovich, 2004): referral and assessment; programming; monitoring of student progress; collaboration between parents and school staff; and reporting. This is described by Boyatzis (1998) as a prior-research-driven approach which has the advantage of extending or refuting prior knowledge. An additional topic emerged in early data collection - social and emotional considerations for the students - and was added to the topics explored in the interviews.

Next, statements that yielded information about parents' judgments about education programs and attributions about students' learning difficulties, as well as explanations of their own actions were identified as the unit of coding (Boyatzis, 1998). Each statement was then coded using an inductive process. Six researchers met to discuss the development of the codes from the first three interviews. Two researchers then independently coded the next five interviews. The author coded the remaining interviews. The trustworthiness of this data was established through the use of multiple experts in the analysis of the data (Clark, 1999) and the thematic analysis, which relied on continuously building on the emerging concepts until clear themes were evident in the data set as a whole (Boyatzis, 1998; Glaser \& Strauss, 1967).

This study relied on coding strategies that have been developed and refined in grounded theory research (Charmaz, 2008), a comparative method that is used to develop general theory (Glaser \& Strauss, 1967). The analysis presented here does not attempt to provide a complete theory, but rather a thematic analysis based on an inductive approach, described above. Charmaz (2008) described grounded theory as an emergent method that also includes abductive reasoning to interpret the theory developed through inductive reasoning. Charmaz identified four strategies that support emergent analyses in grounded theory studies. The first two stages are coding data (using inductive reasoning) and memo writing (to refine themes). Both of these strategies were employed in this study, and I have referred to these as thematic analysis. The next stage is theoretical sampling - the process of seeking additional data in order to "fill out the hidden properties 
of a category" (Charmaz, 2008, p. 167) or theme. As described above, a new topic was identified during data collection and added to the topics discussed in the interviews, which is consistent with theoretical sampling.

The fourth strategy Charmaz (2008) identified was theoretical saturation. Theoretical saturation is the point at which the properties of the categories or themes that have been identified are complete and further data collection does not add new information about the properties of the themes. This stage was not reached in this study. The nursing literature refers to this as partial theory. Keck (1998) noted that "theories derived from the social sciences, [...] are probably exclusively partial theories because there are few, if any, phenomena that have been totally and completely explained" (p. 23).

This study was conducted as part of a larger study (see Underwood, 2008) that included teacher perspectives, which informed the interviews as described above. The themes presented here are part of the broader theory that has been identified in the interview themes above and will continue to be identified in future research. The data presented here include the interpretation of the thematic analysis within the parent involvement literature, current issues in education, and the findings from the questionnaire. The questionnaire data provide important information that inform the interpretation of the themes and will inform theoretical sampling in future research.

\section{Results}

The study's findings yielded information about the nature of parent involvement and engagement in schools, the degree of satisfaction parents had with their involvement or engagement, and how parent involvement and engagement was contextualized within a range of student placements. The results first describe the nature of parent involvement or the current practices and then the affective responses or satisfaction that parents have with these practices. Finally, parents' experiences are described in relation to their perspectives on inclusion.

The iterative coding process described above ultimately resulted in 23 themes identified across the 31 interviews, which are found in Table 1 . The 23 themes resulted in both action items, describing the current practices that parents identified, and affective items that identified their feelings about the process. The themes are identified at the beginning of each section in italics. Pearson correlation coefficients were calculated between items on the questionnaire and with a rating of inclusion derived from the IEP for each student. These correlation data are reported along with the description of the qualitative findings where they provide additional information. Response frequencies for individual items are also provided where they offer information not available from the qualitative information in the interviews.

\section{The Nature of Parent Involvement and Engagement}

Parents described very different relationships with teachers, ranging from parents who were actively involved in trying to influence school policy (engagement) to parents who were passive recipients of information from teachers or who adopted a role that supported teachers' objectives (involvement). Parents took on active roles when they set goals and advocated for supports not in place for their children, particularly seeking resources and accommodations and assessments. Parents took on support roles for teachers when they acted as volunteers at the school and collaborated with school staff by supporting the school's agenda. Considerations that 


\section{Table 1 \\ Thematic Structure}

\begin{tabular}{|c|c|c|}
\hline Topic & Theme & Example statements \\
\hline \multirow[t]{5}{*}{$\begin{array}{l}\text { Referral and } \\
\text { Assessment }\end{array}$} & Sought formal assessment (47) & $\begin{array}{l}\text { "I had to get doctor's notes, I had to take him to } \\
\text { every specialist there is. I got his hearing tested, } \\
\text { and his speech tested, because they thought he } \\
\text { had a learning disability." }\end{array}$ \\
\hline & Placement or location of program (23) & $\begin{array}{l}\text { "We need to find out if from the school board what } \\
\text { would happen if she were in learning disabilities, } \\
\text { the label... or Asperger's or gifted. Would that mean } \\
\text { her home school with assistance?" }\end{array}$ \\
\hline & Funding (affecting referral for service; 10) & $\begin{array}{l}\text { "The only thing is the government has tended to cut } \\
\text { back so unless she's completely physically dis- } \\
\text { abled, she's a threat to other children, or a threat to } \\
\text { herself they'll only cover her to a certain point." }\end{array}$ \\
\hline & Transferred to a new school (8) & $\begin{array}{l}\text { "This is a touchy issue here because we've had a } \\
\text { really good experience in this school and a really } \\
\text { bad experience in this school. Last year we left this } \\
\text { school for } 6 \text { months because of it and we came } \\
\text { back because it is our home school." }\end{array}$ \\
\hline & Family finances limit options (5) & $\begin{array}{l}\text { "I want to get him some sensory integration therapy. } \\
\text { It's very, very expensive and he's been on a waiting } \\
\text { list for two years." }\end{array}$ \\
\hline \multirow[t]{5}{*}{ Programming } & Sought resources/accommodations (48) & $\begin{array}{l}\text { "What I've done now is I have some occupational } \\
\text { therapy in the home." }\end{array}$ \\
\hline & Helped with homework (34) & $\begin{array}{l}\text { "Basically, what I work more with him at home is } \\
\text { reading and I know his reading has improved a lot." }\end{array}$ \\
\hline & Hired a tutor (15) & $\begin{array}{l}\text { "I would have them come over during summer } \\
\text { break, have a student come over, but I gave that } \\
\text { up. It wasn't doing anything." }\end{array}$ \\
\hline & Funding (affecting program; 12) & $\begin{array}{l}\text { "I mean if there was more funding, more of this, } \\
\text { then there'd be a lot more help." }\end{array}$ \\
\hline & Grade retention (11) & $\begin{array}{l}\text { "I don't see any difference from kindergarten to } \\
\text { grade } 1 \text { to grade } 2 \text {. I started getting concerned. I } \\
\text { didn't understand how they could put her in another } \\
\text { grade when she didn't get grade } 1 . "\end{array}$ \\
\hline \multirow[t]{3}{*}{ Monitoring } & Advocated for child (40) & $\begin{array}{l}\text { "Well I have a letter from the Ministry. I fought it } \\
\text { across the province and it came down to the wire } \\
\text { and I did finally receive written documentation" (on } \\
\text { conflicting information about criteria for funding). }\end{array}$ \\
\hline & $\begin{array}{l}\text { Parent knowledge of student communication } \\
(27)\end{array}$ & $\begin{array}{l}\text { "He started when he was about a year old. His } \\
\text { speech wasn't very good and he'd make noise and } \\
\text { grunt and point. And whenever he'd talk you } \\
\text { wouldn't really understand him, but I knew what he } \\
\text { wanted. Like I mean a mother, you know." }\end{array}$ \\
\hline & Balance in parent's life (22) & $\begin{array}{l}\text { "I was going through nursing school and trying to } \\
\text { take care of myself and then be a mother at the } \\
\text { same time." }\end{array}$ \\
\hline
\end{tabular}


Table 1 (Cont'd)

Thematic Structure

\begin{tabular}{|c|c|c|}
\hline \multirow[t]{3}{*}{ Collaboration } & Set goals (17) & $\begin{array}{l}\text { "I always make changes (to the goals). I never sent } \\
\text { an IEP back exactly how I got it." }\end{array}$ \\
\hline & Collaborated with school (7) & $\begin{array}{l}\text { "We're on a first name basis. They phone me per- } \\
\text { sonally, they'll request meetings, they'll send letters } \\
\text { home. Or I call them personally. So it's very open } \\
\text { communication." }\end{array}$ \\
\hline & Volunteered at school (6) & $\begin{array}{l}\text { "I come in once a month, but I haven't been in the } \\
\text { last two months because I was getting ready for } \\
\text { Christmas... I don't know if other parents have a } \\
\text { day or if you have to sign up. I don't know how it } \\
\text { works." }\end{array}$ \\
\hline \multirow[t]{2}{*}{ Reporting } & Met with school staff (41) & $\begin{array}{l}\text { "Meetings, l'll come. They'll phone me and I'm here } \\
\text { within } 2 \text { minutes." }\end{array}$ \\
\hline & IEP document (30) & $\begin{array}{l}\text { "I like them (IEPs) because it tells you what your } \\
\text { kid's doing and what they're going to focus on." }\end{array}$ \\
\hline \multirow[t]{4}{*}{$\begin{array}{l}\text { Non-academic } \\
\text { considerations }\end{array}$} & Student's independence/self-esteem (41) & $\begin{array}{l}\text { "When they didn't realize she had a learning disabil- } \\
\text { ity and she'd put her full effort in and get a D, her } \\
\text { confidence went way down." }\end{array}$ \\
\hline & Student's social interactions/bullying (10) & $\begin{array}{l}\text { "There's a couple of kids that are on the rough side. } \\
\text { I guess sometimes the school takes it that it's his } \\
\text { way, that is why he doesn't have so many friends." }\end{array}$ \\
\hline & Balance in student's life (5) & $\begin{array}{l}\text { "You have to give him a little break too. You can't } \\
\text { hit the books 24/7." }\end{array}$ \\
\hline & Labelling/stigma (5) & $\begin{array}{l}\text { "But when you tell your family (that she has an IEP) } \\
\text { they kind of look at you funny. Like, what does she } \\
\text { need that for? She's perfectly fine. Like it's a bad } \\
\text { thing, but it's not. It's going to make me cry." }\end{array}$ \\
\hline
\end{tabular}

Note. Numbers indicate instances of articulation.

informed parents' involvement and engagement in schools included parents' own knowledge of their child's communication skills, the parents' own school experience, and parents finding balance between supporting their child and their own busy lives. These experiences are identified in the coding structure presented in Table 1.

One form of parent involvement described in the interviews was volunteering in schools. This is an activity that brings parents into schools as a support for the teachers and is a typical parent involvement practice. Parents described volunteering in their children's classes with mixed results. Parents reported that some students found it distracting to have their parents present. For this reason, several parents found ways to volunteer in the school without direct involvement with their own children's classes. Volunteering allowed parents to be more directly involved in the school community, but it was always at the discretion of school staff and did not lead to parents' active engagement in their own child's learning.

The vast majority of descriptions of parent interactions with teachers involved teachers informing parents of the school program and updating them on student progress. All parents in the study described at least one interaction of this type. Parents learned about their children's progress and school planning from IEPs and Ontario report cards as well as through communication with teachers. Very few of the parents were asked to contribute information on the IEP or in 
any other planning activity. The IEP was used as a tool for the school to inform parents, not the other way around. Interestingly, being informed was important to parents. One mother described when a teacher decided to change from using a modified program (work at a lower grade level) to an accommodated program (at grade level). The teacher expected the student's marks to fall somewhat, and the mother explained that "if he had just gone ahead and done it, I would have gotten her report card and gone, 'Oh my god, what's happening?"," Instead, the teacher explained the change to the mother and she was happy with the new program.

In addition to receiving written documentation of students' progress and program, all parents described going to meetings with teachers. In accordance with Ontario education policy, meetings were held with regard to the IEP and Ontario report card. Parents also had informal meetings with classroom teachers, resource and special education teachers, itinerant support teachers, and anyone who had information about their children. In addition to meetings, there were many phone calls home informing parents of their children's progress. These interactions were characterised by teachers reporting student progress to parents with little input from the parent to the teacher. Many parents explained that they did not need to give direct input because teachers were doing a good job. However, of the 31 parents in the study, 21 of them described ways in which they contributed to goal setting for their children.

Overall, parents described overwhelming support for the practice of teachers; however, when parents had a concern that their children's needs were not being met, they described changing their patterns of interaction. In cases where parents felt that their children were not getting the support they needed, they would engage in advocacy for change. Across the 31 interviews, 18 parents described themselves as having taken an advocacy role at some time in their child's education, with 40 references to advocacy across the interviews. The acts of advocacy ranged from actively lobbying the classroom teacher to change his or her classroom practice to legal action and board level pressure to meet their children's needs. Amanda ${ }^{2}$, the mother of a boy in Grade 3, reported being very active in securing support for her son, Alexander. Several teachers at Alexander's school suggested that he would not have the kind of supports in place for him if his mother was not so vocal. Amanda said,

I have found, over the years, that if I have something that I feel is important, I'll go talk to the teacher. I will talk to the program support teacher. I will talk to the principal. Actually, I will talk to anybody who has an ear, in this school... because if one person knows, it kinda might get shoved under the rug, but if everybody knows it's a little bit harder to shove it underneath the rug, you know?

Descriptive findings from the questionnaire data confirmed varying degrees of parents' involvement and engagement in developing the IEP for their children. Eighteen of the 31 parents in the study reported that they were actively or very much involved in the development of the IEP for their children. However, 13 of the parents reported that they were not at all, rarely, or only somewhat involved in the development of the IEP. These findings were consistent with parents' descriptions of very different relationships with teachers that ranged from being passive recipients of information to being actively engaged in school policy and planning.

\footnotetext{
${ }^{1}$ All quotes are verbatim except where they have been minimally altered to improve readability.

${ }^{2}$ All names of people, schools, and locations used in this paper are pseudonyms.
} 


\section{Parent Satisfaction with Their Relationship with Teachers}

Overall, parents described in the interviews a great deal of satisfaction with their children's teachers. For example, one parent said, "You can't thank the teachers enough. They really want to help [my daughter] and she knows that." However, the questionnaire data indicated varying degrees of satisfaction with the IEP development. Eighteen of the parents in the study reported that they were very or somewhat satisfied with their involvement in developing the IEP for their child. The remaining 13 parents were either neutral or not satisfied with their involvement in IEP development. It may be that in the interviews the parents were less inclined to disclose dissatisfaction with their children's teachers than they were when asked specifically about IEP development on the questionnaire. The type of relationship - along the continuum between involvement and engagement - that parents had with teachers did not appear to be related to their satisfaction with the relationship. Instead, parent satisfaction appeared to be linked to the level of improvement children showed over the course of the school year rather than parent involvement or engagement in goal setting for their children, as reported below. This indicates that these parents may understand their involvement or engagement as a strategy for student achievement rather than as a goal in and of itself.

As noted previously, the majority of the parents $(n=21)$ indicated on the questionnaire that they had been involved in developing goals for their children on the IEP. The 10 parents who did not describe involvement in goal setting indicated in the interviews that the goals set by the school were appropriate and adequate. When parents described participating in goal setting it was often because they saw a problem with the goals the school had set for their children. Diane, the mother of Nigel who is in Grade 6, used the IEP as a contractual agreement in which she put her wishes in writing:

I'll go over the IEP five or six times, rewrite stuff, change stuff. They don't have to accept it but at least here they've been fairly good about accommodating my petty needs. [Interviewer: What kind of stuff do you scribble about?] Sometimes it's the terminology they use, sometimes it's they haven't recognized the need in a manner that I feel is appropriate for Nigel.

Parents reported being satisfied with school planning when it is evident to them that program goals are consistent with the needs of their children as they develop and learn. Some parents, however, felt that once the IEP was in place it was rarely changed to reflect growth and learning. Satisfaction with goal setting for the parents was evident when parents saw appropriate revision of the goals from one year to the next. When children have an IEP in place parents expect it to reflect the progress that children make over time or to address the lack of progress by reassessing teaching strategies. Amanda reported becoming engaged in the process of goal setting when she felt it was necessary, despite the fact that she did not feel heard:

I feel that there should be more in his IEP, from year to year. He's improved so much...I'll sit there in a meeting and talk about, 45 minutes, about (my son) and the improvements that he's made, because somebody has to. [Interviewer: Do you see that come out in the IEP after you sit in the meeting and say that?] Not really.

Conversely, parents were pleased when they saw changes over time that were responsive to their children's needs. Diane was similarly engaged in the process of goal setting through her contribution to the IEP. She was satisfied with the process because, unlike Amanda, she felt heard: 
If you notice something at home that the IEP missed, well, you can write it down and say, "Well, here. You missed this," like, "What about that?"

As expected, parents engaged in the IEP process also felt engaged in their children's learning overall; however, these parents were not necessarily co-constructing the teaching and learning strategies and/or goals for their children. All of the parents who tried to help in development of goals set for their children could be characterised as being "engaged" in their children's learning, regardless of how the school responds. The degree of satisfaction that parents feel from this process is affected by the response to their input. These parents are expected to attend many more meetings than other parents. Ontario education policy requires schools to have both report card meetings and IEP review meetings. While all parents described enormous demands on their time from meetings and communicating with staff, along with the many other responsibilities in their busy lives, none complained about communicating with school staff. The expectations and requirements of the school system could be interpreted to mean that parents are simply complying through their involvement in meetings, but parents described more than compliance. These parents were highly engaged with their children. Dana communicated with the school regularly:

Because I know it is for the best interests of Robert. And they're gonna tell me how he's doing. They'll say, "Well, there's a problem here, problem here. Okay, well what's our next move?" Or if he's doing well, well it, you know, I mean, it makes me proud!

The communication between staff and parents, however, can take an emotional toll. Amanda said,

Sometimes the meetings go pretty good, and sometimes I will leave in tears. You know, I will. I will leave in tears. I don't let them see that. It's just it gets to be a little...I don't know if it's because it's been so many years, and... it seems like I hear the same things every time I go.

Questionnaire data indicated a positive correlation between parent satisfaction with their involvement or engagement in developing the IEP and ratings of their children's level of improvement over the course of the school year $(r=.67, p<.01)$. Conversely, parent satisfaction with their involvement or engagement in IEP development was negatively correlated with parent ratings of involvement or engagement in supporting the goals on the $\operatorname{IEP}(r=-.55, p<.01)$. This is consistent with the interview data which indicated that parents' satisfaction corresponded to how well their children were doing rather than the amount of time they spent at the school. This indicates that it is important for involvement and engagement policies to be flexible and responsive to circumstances.

\section{Parent Involvement and Engagement and Inclusive Placement}

Parents did not universally hold a view that inclusion-placement in a non-segregated setting - was a better placement. Parents were more concerned with the individual needs of their child than defining one placement as the most appropriate setting. Christopher is in a segregated class this year, after being in an inclusive placement the previous year. His mother, Elizabeth said, 
I'm really happy with his teacher this year and, uh, even last year. They tried to help him. And I think he feels better than in a normal class. And this year I could notice he improved a lot. I think this kind of class was better for him but at the same time I think it's better if next year we try to integrate him.

Patricia's son, David, is in an inclusive class this year, but his teacher has suggested his mother look into a segregated school. Patricia said, "If I find that this program isn't helping him anymore then of course I'd move to another program."

Parents cannot easily choose a program that fits with their own belief about what constitutes the best program. Parents exercised choice by selecting schools with a philosophy that matched their own. While this practice is not a school policy to engage parents, parents are able to exercise choice by moving between the Catholic and Public school boards (both are publicly funded) in their district and some parents are able to move residences so they can be in the school district of their choice. Eight parents in the study had moved in order to find what they considered to be a better placement for their child. This practice, of course, requires resources on the part of the family who will need to navigate the change from one system to the next and/or to have the financial resources to move.

All of the parents in the study considered the social impact of school placement to be a primary concern, in particular students' independence and self-esteem, social interactions and bullying, labelling and stigma, and balancing social and academic issues were of concern to parents (see Table 1, non-academic considerations). Beverly saw the benefits her daughter Catherine had from placement in an inclusive classroom:

It's a good placement because she needs the integration because they have such poor social skills. What was happening before when she was in the isolated classroom with all kids who did have behaviour problems is that she was picking up behaviour problems.

Amanda, on the other hand, commented that her son Alexander is

starting to even have a [negative] attitude towards adults, because basically he is not being a kid right now. He's being taken out of his classroom so much that how can he learn to play with children his own age, you know?

Diane, after several years of fighting for an inclusive placement for her son, said that Nigel will go to a segregated program for high school:

[Nigel] wants to go to Davisville (a high school with an inclusive program) because he doesn't want to be in an associated class (a self-contained class) but I think the more he understands, the more he works outside of the classroom here-which we hadn't let happen for the first few years - we wanted him totally integrated for the social skills more than anything. [...] It'll depend on where he is intellectually at the time.

The questionnaire data indicated a weak positive correlation between parent satisfaction with their involvement in IEP development and students being in an inclusive placementdefined as being in a regular education placement as reported on the IEP $(r=.38, p<.05)$. Because the interview data, as described earlier, linked parent satisfaction with parent perceptions of student achievement, it could be argued that students with more severe disabilities are more likely to be in self-contained classes with more intensive supports. Severity of the disability could then explain the level of achievement, which is tied to parent satisfaction. However, the 
students' placements in this study appeared to directly reflect the philosophy of the school boards rather than the characteristics of the students. Six of the seven students in self-contained or partial withdrawal placements were considered to have mild disabilities. Parents' appeared to be pleased with the school when their child was doing well, regardless of the nature of the placement. Additionally, parents' understanding of achievement was closely aligned with their understanding of their own children.

\section{Discussion}

From the interviews in this study a complex picture of parent involvement and engagement emerged. To begin, the continuum of involvement to engagement varies depending on the circumstances. All of the parents expressed at least some level of support for the teachers who worked with their children and their involvement activities reflected this support. Parents acted as volunteers; they helped children with homework sent from the school; and they received and usually read the many documents, particularly the IEP and report card, from the school that were designed to keep them informed of the school's activities. These activities can be characterized as parent involvement, but arguably they do not illustrate engagement. The parents, however, described these activities in a positive way, with most feeling that being informed by the school and participation in activities that support school goals are important to them.

\section{Parent Engagement}

The parents in this study also described particular circumstances where they did not feel the school was meeting the needs of their children. In these situations, the parents described two ways in which they fostered change. These parents engaged in direct input into the decision making and programming goals for their children by talking to as many school and board personnel as they could or re-writing the IEP in great detail. This direct input is most closely aligned with the role of engaged parents described in the literature (Government of Ontario, 2005; Pushor \& Murphy, 2004), but it is the least common role described by parents in this study. Parents in this study were more likely to change schools when there was a problem. This indicates a lack of engagement with the school but a high degree of engagement with their own children's learning, assuming that changing schools involves some degree of disruption within families. Additionally, changing schools likely requires parents to navigate the rules about school boundaries and in some cases to find resources to move house or make other arrangements to live in a school district. This raises issues about the equity of parent choice through selecting schools since not all families have the same level of resources. This also speaks to how well schools respond to parents who are engaged in their children's learning. In these circumstances, parents' do not experience empowerment, and the call to transform the system, as described in the Parent Voice in Education Project (Government of Ontario, 2005) becomes all the more clear. Parents need the required "consultation" on IEPs to include responsiveness to their concerns.

Parents described selecting schools that were in systems with a philosophical approach that matched their own. It may be that the system level differences for these parents were more difficult to negotiate than the differences that other parents had with individual teachers, and consequently, these parents moved to systems where they felt they were more likely to be able to engage with individual teachers. When parents felt that the individual program did not reflect 
their children's needs, there was inadequate supervision, or their child was not achieving his or her potential, parents were pushed to become advocates. While the most engaged parents often experienced conflicting positions with teachers, it is important to consider that it was through these experiences that they had the most control over decision making and were able to voice their opinions. Parents wanted to have the information that came from passive reception of information, but they also wanted to be heard. Crozier and Davies (2007) similarly found that South Asian parents in UK schools were not highly involved in their children's education, but that this did not mean these parents were not interested in being involved or engaged. They concluded that schools were not welcoming to these parents. Based on the findings in this study, it is recommended that parent and teacher involvement and engagement practices be responsive to circumstances and accept parent involvement and engagement that is both passive and active from the perspective of the school. Further, this continuum of involvement to engagement must acknowledge the fact that some parents will not become involved at the school, but this does not mean that the parents are not engaged with their children's learning at home. Lightfoot (2004) cautioned against "dividing parents into those who give and those who take, or those who are empty and those who are full" (p. 93). Instead, parent involvement and engagement practices may be viewed as fluid, with parents and teachers negotiating their degree of participation and working through conflicting views about how to meet the needs of students.

\section{Student Outcomes}

This study indicates that while parent involvement and engagement are important to parents, parents are more concerned with how well their children are doing in school. Parent satisfaction with their children's school programming and relationships with teachers is associated with parent perceptions of children's academic and social achievement. Parents wanted individualized planning that was consistent and responsive to their child's development. Increased parent engagement did not necessarily lead to increased satisfaction for parents. This makes sense since the most engaged parents are in an advocacy role, usually resulting from the perception that their children were not receiving good support. Parents who felt heard in meetings were the most satisfied with their children's program.

Whether parents are highly involved or engaged, or not, they expect the school to be responsible for their children's learning. This is not necessarily consistent with professional views of the role of parents in student achievement. The literature claims that parent involvement or engagement practices lead to student achievement (Bouffard \& Weiss, 2008; Epstein, 2001b; Hughes \& Kwok, 2007; Jeynes, 2007). Yet, there is criticism of this claim and challenges to the notion that there is a direct causal link between parent involvement and student achievement (Domina, 2005; Flessa, 2008). The current study indicates that the degree to which parents are involved or engaged is influenced by student achievement making the causal relationship between these variables bidirectional. This finding indicates that responsibility for student outcomes must be shared by teachers and parents given that both are charged with improving children's outcomes. Thus it is important that teachers work toward making school environments welcoming and responsive to parent inputs in order to achieve engagement, which is equitable for all parents and acknowledges that parents may not agree with educator perspectives. 


\section{Parent Engagement in the Context of Inclusive Education Practice}

Finally, it is important to consider parent engagement within the context of inclusion of children with disabilities in regular classrooms, since this is one of the goals of parent involvement practices for children with disabilities (Mortier et al., 2009). The provincial requirement for parents to be consulted in development of the IEP reflects the belief that parent engagement is critical in inclusive practice. Some of the outcomes that have been linked to inclusive practice include improved social, academic, and behavioural outcomes (Demeris, Childs, \& Jordan, 2007; Rea, McLaughlin, \& Walther-Thomas, 2002; Swanson \& Hoskyn, 1998). If inclusive placements are more successful, as indicated by these research studies, one might expect that parents find it less necessary to be engaged in advocacy and decisions about resources, accommodations, and assessments. However, the parents describe a much more complex picture that illustrates the importance of including parents along with inclusion of their children.

Parents were found to have diverging opinions on inclusive practice. Some felt that inclusive placements provided positive role models, while others felt their children needed a smaller classroom to promote concentration and protect them from stigma. Parents' views on inclusive practice were related to their experience: Children who had succeeded in inclusive classes had parents who supported inclusion. This indicates that the nature of the programs offered in the local school, if successful, can influence parents' beliefs. Parent engagement has been described as a key principle for inclusive education practice. However, the evidence in this study suggests that not all parents want their children to be in inclusive education placements. Although parents have been a driving force in the inclusion movement, parents also hold anti-inclusion attitudes that are one of the most commonly cited barriers to inclusive practice (Palmer, Fuller, Arora, \& Nelson, 2000). Experience, therefore, seems critical in parent attitudes toward inclusive education settings: Parents whose children are in successful inclusive placements are the most likely to support the practice of including students with disabilities in regular education classes. Parents who do not believe their children's needs are being met will not be supportive of the program in place. Thus based on this study's findings, for parents to be supportive of inclusive placement schools must meet the support needs of students. Schools can engage parents through empowering parent voice and creating a welcoming environment in which diverse perspectives amongst families are accepted, particularly when the school program is not meeting the needs of children.

\section{Limitations}

Limitations in this research include the lack of opportunity for parents to check the interpretations of their perspectives through member checks. This was not possible in this study due to the timing of the school year and because parents were identified through the classroom teachers, parents were accessible for the one school year in which their child was in that teacher's room. In future research, this should be addressed. There are also some limitations in the questionnaire data, which include broad questions designed to explore the relationship of parents to the IEP process. In future research, the questionnaire could be informed by the findings of this study. Finally, the definition of inclusion is complex. In this study a scale was derived from IEP data about placement. This is not a comprehensive definition of the inclusion; nevertheless, it allowed some measure of how parent involvement and engagement relate to student placement. 


\section{Conclusions}

In theory, consultation with parents as mandated by the IEP policy appears to fulfil the goals of parent involvement and even engagement if parents have the opportunity to voice their views on the program in place for their children. In practice, it is not always clear that parent involvement policies lead to parent engagement. The experiences of the parent participants in this study suggest that parent engagement is something that happens as a result of parent involvement strategies initiated by schools and through opportunities for parents to have meaningful voice in decision making about their children's educational programs. Future research could examine parent perceptions of more effective ways to include their voices. Parent engagement should be further enhanced by encouraging parents to have an active role that is not only reactive to perceived shortcomings on the part of the school but part of a positive relationship between parents and school staff. Additionally, schools will get better at meeting the needs of children with disabilities in inclusive classrooms when parents have the opportunity for more meaningful interactions with educators in which their opinions are heard and they are accepted as an important part of the decision-making team.

\section{References}

Berman, R. C., \& Wilson, L. (2009). Pathologizing or validating: Intake workers' discursive constructions of mothers. Qualitative Health Research, 19(4), 444-453.

Bouffard, S., \& Weiss, H. (2008). Thinking big: A new framework for family involvement policy, practice and research. The Evaluation Exchange, XIV(1\&2), 2-7.

Boyatzis, R. E. (1998). Thematic analysis and code development: Transforming qualitative information. Thousand Oaks, CA: Sage.

Charmaz, K. (2008). Grounded theory as an emergent method. In S. N. Hesse-Biber \& P. Leavy (Eds.), Handbook of emergent methods (pp. 155-170). New York: Guilford Press.

Clark, A. (1999). Qualitative research: Data analysis techniques. Professional Nurse, 14(8), 531-533.

Corter, C., \& Pelletier, J. (2004). The rise and stall of parent and community involvement in schools. Orbit, 34(3), 7-12.

Crossnoe, R., Erickson, K., \& Dornbusch, S. (2002). Protective functions of family relationships and school factors on the deviant behavior of adolescent boys and girls: Reducing the impact of risky friendships. Youth \& Society, 33(4), 515-544.

Crozier, G., \& Davies, J. (2007). Hard to reach parents or hard to reach schools? A discussion of homeschool relations, with particular reference to Bangladeshi and Pakistani parents. British Educational Research Journal, 33(3), 295-313.

Dabkowski, D. M. (2004). Encouraging active parent participation in IEP meetings. Teaching Exceptional Children, 36(3), 34-39.

Demeris, H., Childs, R. A., \& Jordan, A. (2007). The influence of students with special needs included in grade-3 classrooms on the large-scale achievement scores of students without special needs. $\mathrm{Ca}$ nadian Journal of Education, 30(3), 609-627.

Dodds, J., Saggers, S., \& Wildy, H. (2009). Constructing the ideal family for family-centred practice: Challenges for delivery. Disability \& Society, 24(2), 173-186.

Domina, T. (2005). Leveling the home advantage: Assessing the effectiveness of parental involvement in elementary schools. Sociology of Education, 78(3), 233-249.

Engel, D. M. (1993). Origin myths: Narratives of authority, resistance, disability, and law. Law \& Society, 27(4), 785-826.

Epstein, J. L. (2001a). School, family and community partnerships: Caring for the children we share. In J. L. Epstein, M. G. Sanders, B. S. Simon, K. C. Salinas, N. R. Jansorn, \& F. L. Van Voorhis (Eds.), 
School, family and community partnerships: Your handbook for action (2nd ed.; pp. 7-29). Thousand Oaks, CA: Corwin Press.

Epstein, J. L. (2001b). School, family and community partnerships: Preparing educators and improving schools. Boulder, CO: Westview Press.

Ferguson, P. M. (2002). A place in the family: An historical interpretation of the research on parental reactions to having a child with a disability. The Journal of Special Education, 36(3), 124-130.

Flessa, J. (2008). Parental involvement: What counts, who counts it, and does it help? Education Canada, $48(2), 18-21$.

Glaser, B. G., \& Strauss, A. L. (1967). The discovery of grounded theory: Strategies for qualitative research. Chicago, IL: Aldine Publishing Company.

Government of Ontario. (2005). Parent voice in education project report. Toronto, ON: Queen's Printer for Ontario.

Hanson, M. J., Horn, E., Sandall, S., Beckman, P., Morgan, M., Marqhuart, J., et al. (2001). After preschool inclusion: Children's educational pathways over the early school years. Exceptional Children, 68(1), 65-83.

Harris, A., \& Goodall, J. (2008). Do parents know they matter? Engaging all parents in learning. Educational Research, 50(3), 277-289.

Hauser-Cram, P., Warfield, M. E., Shonkoff, J. P., \& Krauss, M. W. (2001). Children with disabilities: A longitudinal study of child development and parent well-being. Monographs of the Society for Research in Child Development, 66(3), Serial No. 266.

Hughes, J., \& Kwok, O. (2007). Influence of student-teacher and parent-teacher relationships on lower achieving readers' engagement and achievement in the primary grades. Journal of Educational Psychology, 99(1), 39-51.

Jeynes, W. (2007). The relationship between parental involvement and urban secondary school student achievement: A meta-analysis. Urban Education, 42(1), 82-110.

Jordan, A., \& Stanovich, P. (2004). The beliefs and practices of Canadian teachers about including students with special education needs in their regular elementary classrooms. Exceptionality Education Canada, 14(2\&3), 25-46.

Keck, J. F. (1998). Terminology of theory development. In A. M. Tomey \& M. R. Alligood (Eds.), Nursing theorists and their work (4th ed., pp. 16-24). St. Louis, MO: Mosby.

Lightfoot, D. (2004). "Some parents just don't care" Decoding the meaning of parental involvement in urban schools. Urban Education, 39(1), 91-107.

Ministry of Education. (2000). Individual Education Plans: Standards for development, program planning and implementation. Toronto, ON: Queen's Printer for Ontario.

Ministry of Education. (2007). Shared solutions: A guide to preventing and resolving conflicts regarding programs and services for students with special education needs. Toronto, ON: Queen's Printer for Ontario. Available online: http://www.edu.gov.on.ca/eng/general/elemsec/speced/shared.pdf

Mortier, K., Hunt, P., Desimpel, L., \& Van Hove, G. (2009). With parents at the table: Creating supports for children with disabilities in general education classrooms. European Journal of Special Needs Education, 24(4), 337-354.

Ontario Coalition for Inclusive Education. (2003). Statement of principles. Retrieved August 22, 2006, from http://www.inclusive-education.ca/about/principles.php

Palmer, D., Fuller, K., Arora, T., \& Nelson, M. (2000). Taking sides: Parent views on inclusion for children with severe disabilities. Exceptional Children, 67(4), 467-484.

Pushor, D. (2007, January). Parent engagement: Creating a shared world. Paper presented at Ontario Education Research Symposium, Toronto, ON.

Pushor, D., \& Murphy, B. (2004). Parent marginalization, marginalized parents: Creating a place for parents on the school landscape. Alberta Journal of Educational Research, 50(3), 221.

Rea, P., McLaughlin, V., \& Walther-Thomas, C. (2002). Outcomes for students with learning disabilities in inclusive and pullout programs. Exceptional Children, 68(2), 203-222. 
Swanson, H. L., \& Hoskyn, M. (1998). Experimental intervention research on students with learning disabilities: A meta-analysis of treatment outcomes. Review of Educational Research, 68(3), 277321.

Tashakkori, A., \& Creswell, J. W. (2007). Editorial. Journal of Mixed Methods Research, 1(3), 207-211.

Turnbull, A., Turnbull, R., Erwin, E., \& Soodak, L. (2006). Families, professionals and exceptionality: Positive outcomes through partnerships and trust (5th ed.). Upper Saddle River, NJ: Prentice Hall.

Underwood, K. (2008). The construction of disability in our schools: Teacher and parent perspectives on the experience of labelled students. Rotterdam, Netherlands: Sense.

Williams, T., Kirst, M., Haertel, E., et al. (2005). Similar students, different results: Why do some schools do better? A large-scale study of California elementary schools serving low income students. Mountain View, CA: EdSource.

Wink, J. (2005). Critical pedagogy: Notes from the real world (3rd ed.). Upper Saddle River, NJ: Allyn \& Bacon.

\section{Author's Note}

Correspondence concerning this article should be addressed to Kathryn Underwood, Ryerson University, School of Early Childhood Education, 350 Victoria St., Toronto, ON, M5B 2K3.

E-mail: kunderwood@ryerson.ca.

I would like to thank Anne Jordan for her support throughout this project. Thank you also to the very helpful comments from the reviewers of this article.

\section{Appendix}

\section{Parent Questionnaire}

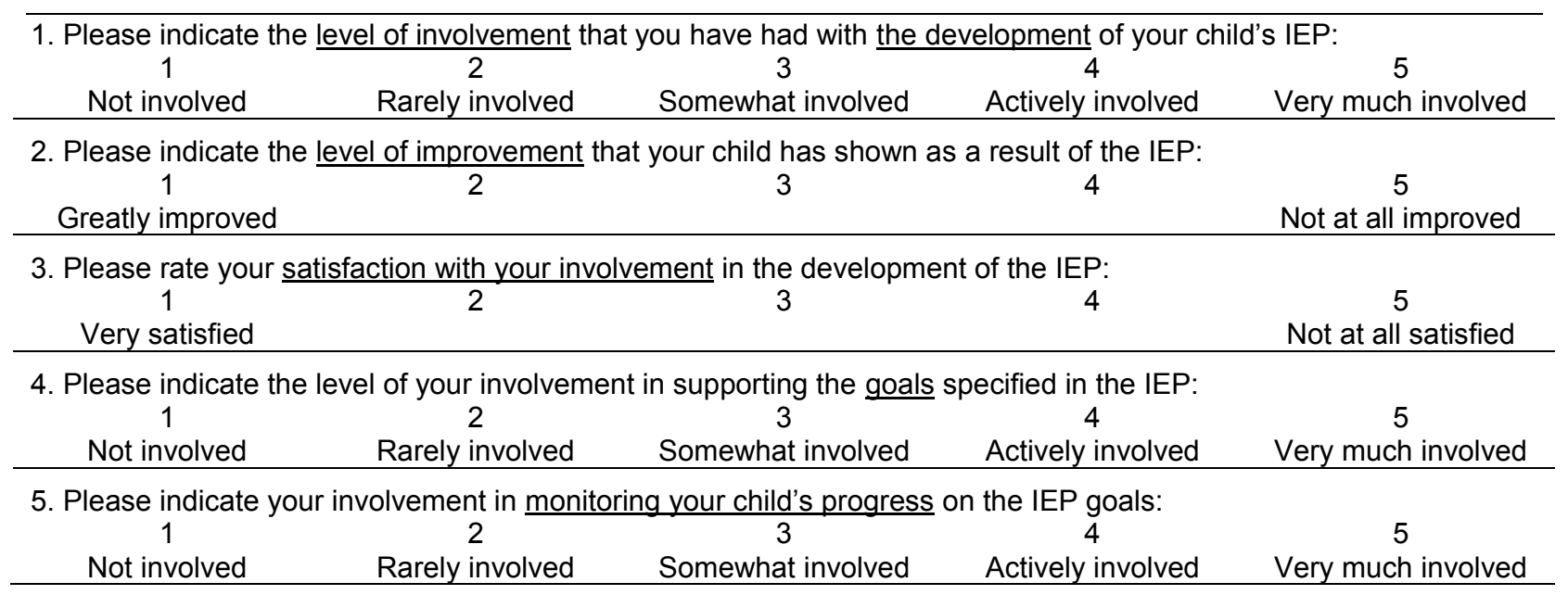

